\title{
ANA, RF and CRP in Patients with Rheumatic Symptoms (SLE and/or RA) in the King Abdul-Aziz Hospital-Jeddah-Saudi Arabia
}

\section{Ahmed Bamujaly}

Medicine College, King Abdul-Aziz University, Jeddah, Kingdom of Saudi Arabia

"Corresponding author: Ahmed Bamujaly, Medicine College, King Abdul-Aziz University, Jeddah, Kingdom of Saudi Arabia, Tel: 00966507835493; E-mail: drmm1918@gmail.com

Received date: February 10, 2017; Accepted date: February 20, 2017; Published date: February 24, 2017

Copyright: @ 2017 Bamujaly A. This is an open-access article distributed under the terms of the Creative Commons Attribution License, which permits unrestricted use, distribution, and reproduction in any medium, provided the original author and source are credited.

\begin{abstract}
Purpose of the research: This study was done to explore the ANA, RF and CRP in the patients with some of Rheumatic Symptoms

Materials and methods: The studies were done for 103 patients with Rheumatic Symptoms and were included in this study and their sera tested for the presence of Antinuclear Antibody (ANA), Rheumatoid Factor (RF), and Creactive protein (CRP).

Results: The results showed that $33 \%$ of the patients with Systemic Lupus Erythematosis (SLE) had+ve ANA, the remainder $67 \%$ of patients were with Rheumatoid Arthritis (RA), the incidence of SLE was 4: 1 female to male while of RA was 2: 1. The highest titers of ANA, RF, and CRP were in females. In the following age groups (10-14), $(15-19)$ and (35-39) the incidence of SLE were in females only. No male or female with SLE in (40-44), (45-49) or (50-54).

Conclusion: The patients cleared that most patients were harmed either by Rheumatoid Arthritis or +ve AntiNuclear Antibody when they had Systemic Lupus Erythematosis.
\end{abstract}

Keywords: Rheumatic symptoms; Rheumatoid arthritis; Systemic lupus erythematosis; Antinuclear antibody

\section{Introduction}

Immunodiagnostic or serodiagnostic studies of antibody reactions are used for diagnosis of the infectious disease, autoimmune disease, immune allergies and neoplastic disease in such kind of studies blood serum is tested for antibodies against particular antigens [1]. Pathologically, autoimmune disorders are produced by autoantibodies that are directed against self-antigens example, including systemic rheumatic diseases such as rheumatoid arthritis and systemic lupus Erythematosis [2]. An increasing number of autoantibodies can be detected. Production of some of these is a common and age-related phenomenon that may be exaggerated by chronic inflammation. Their mere presence, therefore often has low diagnostic specificity and little clinical relevance. If present in high concentration, however, their disease specificity often increases. It is therefore important to know how much antibodies are present (the titer or concentration in units) rather than just whether they are detectable. The correct choice and interpretation of these tests depend on detailed knowledge of the patient. Different detection and assay systems exist for many of these autoantibodies, and close liaison with the local immunology service required $[3,4]$.

Anti-Nuclear Antibody (ANA), Rheumatoid Factor (RF) and Creactive protein (CRP) are among the three most frequently used as non-specific markers of autoimmunity and can occur alone or in conjugation with autoantibody specificity in rheumatic diseases [5] The blood of many persons with Rheumatoid Arthritis (RA) contains macroglobulin- type antibodies called Rheumatoid Factor (RF). Evidence indicates that RF is anti-gamma globulin-antibodies; however, until a specific antigen that produces RF is discovered, the exact nature of RF can only be speculated. Even more uncertain is the role that plays in RF. Although RF may cause or perpetuate the destructive changes associated with rheumatoid arthritis (RA), it may also beneficial to these changes or may even serve some beneficial purpose. RF is sometimes found in sera from patients with other diseases, even though RF incidence and values are higher in patients with (RA) [1].

During many inflammatory, a specific abnormal protein named CReactive Protein (CRP) appears in the blood, this protein is virtually absent from the serum of healthy persons. CRP is one of the most sensitive acute phase reactants. Levels of CRP can increase dramatically (100 fold or more) after severe trauma, bacterial infection, inflammation, surgery or neoplastic proliferation. Measurements of CRP have been used historically to assess activity inflammatory disease, to detect infections after surgery, to detect transplant rejection, and to monitor these inflammatory processes [2]. Measurement of Anti-Nuclear Antibody (ANA) in serum is the most commonly performed screening test for autoimmune bodies in patients suspected of having systemic rheumatic disease (SİRD), S.RD, includes Systemic Lupus Erythematosis (SLE), mixed connective tissue disease, Sjogren syndrome, scleroderma (CREST) calcinosis, Rayaunds phenomenon, esophageal dysfunctions, sclerodactly and telangiectasia syndrom, rheumatoid arthritis and polymyositis [3]. The aim of this work is to study ANA, RF and CRP and their titers in patients of SLE and RA in correlation with age and sex. 


\section{Materials and methods}

\section{Patients}

A total number of 103 patients with rheumatoid symptoms were included. The patients were admitted to The King Abdul-Aziz Hospital from June 2015 to June 2016. Subjects included in this study were divided into following groups presented in (Table 1).

\begin{tabular}{|c|c|c|c|c|c|c|}
\hline Disease & No. & $\begin{array}{l}\text { Age } \\
\text { Range }\end{array}$ & $\begin{array}{l}\text { Female } \\
\text { no. }\end{array}$ & $\begin{array}{l}\text { Age } \\
\text { Range }\end{array}$ & $\begin{array}{l}\text { Male } \\
\text { no. }\end{array}$ & Diagnosis \\
\hline SLE & 36 & Oct-39 & 28 & Oct-39 & 8 & $\begin{array}{l}\text { Depended on } \\
\text { recognition of } \\
\text { specific symptoms } \\
\text { and identifications of } \\
\text { autoantibodies. } \\
\text { Some of the } \\
\text { common symptoms } \\
\text { are butterfly, rash, } \\
\text { photosensitivity, and } \\
\text { anemia. }\end{array}$ \\
\hline RA & 67 & $20-54$ & 44 & $20-54$ & 23 & $\begin{array}{l}\text { The typical clinical } \\
\text { phenotype of its } \\
\text { asymmetric, and a } \\
\text { deforming and large } \\
\text { small and polyarthritis of } \\
\text { joints pociated with } \\
\text { ten associc } \\
\text { symmetric } \\
\text { disturbance and } \\
\text { extrarticular disease } \\
\text { feature. The clinical } \\
\text { course is life long, } \\
\text { with intermittent } \\
\text { exacerbation and } \\
\text { remission. }\end{array}$ \\
\hline
\end{tabular}

Table 1: Number, age and diagnosis of patients with SLE and RA.



Figure 1: Diagnosis for rheumatic symptoms.

The samples were chosen according to the diagnoses that were done to the patient with Rheumatic Symptoms, and tests to them for checking the presence of ANA, RF, and CRP in the King Abdul-Aziz
Hospital. All patients were referred to Immunological Laboratory of the two medical centers (Figure 1).

Blood Collection and manipulation: All samples were clotted at room temperature, centrifuged and the sera stored at $20^{\circ} \mathrm{C}$ until used in the assays.

Rheumatoid Factor Test was assayed by the latex test Linear Chemicals, rapid agglutination, the determination is made by agglutination of the latex suspension with human gamma globulins in front of RF that found in the serum samples.

C-reactive protein Test is considered a rapid slide agglutination procedure (Linear Chemicals) that is based on a modification of the latex fixation method, developed for the detection and semiquantization of C-RP in serum. The assay is performed by testing a suspension of latex particles coated with antihuman CRP antibodies against unknown serum. The presence of the CRP level above the upper limit of the reference interval in the sample was tested.

Antinuclear Antibody test (SLE) is intended to be used as an aid in the diagnosis of Systemic Lupus Erythematosis through the detection and quantization of SCTUII antinucleoprotein factors associated with SLE. It detected the antinuclear antibody is agglutination of coated particles. The antibodies that are believed to be most characteristic of SLE are these that are directed against deoxyribonucleoprotein (DNP). The principle of this test is based on the agglutination reaction between latex particles coated with DNP (TDS company) being brought into contact with a serum, which contains antinuclear antibody. Agglutination indicates a positive reaction. The reaction time for this occurrence is within one minute.

\section{Results}

\begin{tabular}{|l|l|l|l|l|}
\hline $\begin{array}{l}\text { Age } \\
\text { ranges }\end{array}$ & $\begin{array}{l}\text { Total No. } \\
(\%)\end{array}$ & $\begin{array}{l}\text { ANA (+VE no } \\
\%)\end{array}$ & $\begin{array}{l}\text { RF (+VE no } \\
\%)\end{array}$ & CRP (+VE no \%) \\
\hline Oct-14 & $1(1.4)$ & $1(104)$ & $1(100)$ & $1(100)$ \\
\hline $15-19$ & $5(6.9)$ & $5(100)$ & $5(100)$ & $5(100)$ \\
\hline $20-24$ & $3(11.1)$ & $6(75)$ & $8(100)$ & $8(100)$ \\
\hline $25-29$ & $13(18)$ & $6(46.2)$ & $13(100)$ & $9(69.2)$ \\
\hline $30-34$ & $19(26.4)$ & $5(26.3)$ & $15(100)$ & $11(58)$ \\
\hline $35-39$ & $20(27.8)$ & $5(25)$ & $18(90)$ & $9(45)$ \\
\hline $40-44$ & $3(4.2)$ & 0 & $3(100)$ & $1(33.3)$ \\
\hline $45-49$ & $2(2.3)$ & 0 & $2(100)$ & 0 \\
\hline $50-54$ & $1(1.4)$ & 0 & $5(100)$ & 0 \\
\hline
\end{tabular}

Table 2: Numbers and Percents of female patients with ANA +ve, RF $+\mathrm{ve}$ and $\mathrm{CRP}+\mathrm{ve}$ with age ranges.

In table 2 and table 3 the numbers and percentages of female and male patients positive (+ve) for ANA, RF and CRP are presented respectively together with ages, The female: male ratios in SLE patients was 4: 1 while for RA was 2: 1 . The peak age incidence of SLE was 24 years, while that for RA 30 years to 34 years. In male group there was no patients with SLE the following groups 10-14, 15-19 and 50-54, the incidence of SLE in the age range 10-19 was only in females. The peak age incidence of SLE and RA was 35-39 years the percent was $27.8 \%$ of 
total number of female patients. The peak age incidence of male with SILE and RA was 25- 29 and 30-34 respectively the percent was $32.3 \%$ of total number of male patients. In age groups (Table 3) 10-14 and 15-19 all patients had a (+ve ANA), (+ve RF) and (+ve CRP). All patients with SLE had a (+ve ANA), (+RF) and (+ve CRP). While in RA patients not all patients had a RF had +ve CRP except the age group 20-24. Two pf 35-39 had -ve RF but +ve CRP but they diagnosed as RA patients according to clinical manifestation. In 40-44 only one of RA patients had +CRP, while in age groups $45-49$ and 50-54, no patients had five CRP. ALL patients with SLE had +ve RF and +ve CRP but not all patients with RA had +ve CRP.

\begin{tabular}{|c|c|c|c|c|}
\hline $\begin{array}{l}\text { Age } \\
\text { ranges }\end{array}$ & Total No (\%) & $\begin{array}{l}\text { ANA } \\
\%)\end{array}$ & $\begin{array}{lll}\text { RF } & \text { (-VE no } \\
\%) & & \end{array}$ & $\begin{array}{l}\text { CRP (-VE no } \\
\%)\end{array}$ \\
\hline Oct-14 & 0 & 0 & 0 & 0 \\
\hline $15-19$ & 0 & 0 & 0 & 0 \\
\hline $20-24$ & $5(15.2)$ & $3(52)$ & $5(100)$ & $3(52)$ \\
\hline $25-29$ & $10(32.3)$ & $2(20)$ & $10(100)$ & $5(30.2)$ \\
\hline $30-34$ & $10(32.3)$ & $3(30)$ & $10(100)$ & $6(53)$ \\
\hline $35-39$ & $3(9.7)$ & 0 & $3(100)$ & $1(33.3)$ \\
\hline $40-44$ & $2(4.2)$ & 0 & $2(100)$ & 0 \\
\hline $45-49$ & $1(3.2)$ & 0 & $1(100)$ & 0 \\
\hline $50-54$ & 0 & 0 & 0 & 0 \\
\hline
\end{tabular}

Table 3: Numbers and Percent of male patients with ANA +ve, RF +ve and CRP +ve with age ranges.

\section{Discussion}

SLE is the most common multi system connective tissue disease. It is characterized by a wide variety of clinical features and diverse spectrum of autoantibody production. RA is the most common inflammatory and has an important case of potentially preventable disability. Many of the clinical features and management strategies in RA are relevant across the spectrum of inflammatory disease [4,6-8]. In our study $65 \%$ of patients were with RA while $35 \%$ of patients werewith SLE, our RA percent similar to Julius et al. [9]. In this study all patients with+ANA were with SLE while in others ANA have been detected in less than $10 \%$ to greater than $70 \%$ of patients with RA $[10,11]$, they found that $7.5 \%$ of RA patients were+ANA and RF -ve. The peak age incidence in the recent study was differ from that others, in the recent were (20-24) of SLE and (30-34) of RA, while the west last studies found that the peak age incidence of SLE (15-25) and (25-35) of RA. The incidence of SLE in female to male (4:1) and of RA (2:1) and this is differs from the last studies where the incidence of SLE in female to male $(9: 1)$ and RA (3:1). An increasing number of auto antibodies can be detected. Production of some of these is common, age related phenomenon that may be exaggerated by chronic inflammation. Their presence were, therefore, often has low diagnostic specificity and little clinical relevance. If present in high concentrations, however, their disease specificity often increases. It is therefore important to know how much antibody is present (the titer or concentration in unit) rather than just whether it is detectable [3]. The results show that the highest titers of some rheumatic diseases parameters (ANA, RF and CRP) were in females, this might due to the more sensitive immune response in female than male, in most non-rheumatic conditions, titers of RF are lower than in RA [12]. The specificity of the RF reaction for RA increases with serum titers [13], and this differs from what was found in the recent study, because we found that the highest titers of RF was in the patients with SLE. At least 50 auto antigenic targets for the auto antibody production described in the SLE. However, none of the diverse manifestations of SLE can be attributed to single antigenic stimulus, and likely that this wide spectrum of auto antibody production result from polyclonal. Many auto antigens in SLE are components of intracellular and intranuclear machinery. B and T cell activation.

In normal health these antigens are hidden from the immune system and do not provoke an immune response. Although the triggers that lead to auto antibody production in SLE are unknown, one mechanism may be expression of novel antigens on the cell surface during apoptosis. This hypothesis is supported by the fact that environmental factors that associated with flares of lupus increase oxidative stress and subsequent apoptosis. Such factors include exposure to sun light and artificial UV light, pregnancy and infection 3 or may be due to some genetic factors, so further analysis in families have a history of RA and SLE may be helpful in predicting the detection of immune response and precise genetic susceptibility to RA and SILE, it will also be useful to include other gene markers like oil anti trypsine, which are thought to be associated with severe seropositive RA and SLE [13] from (Table 3 and 4) we can conclude that the incidence of SLE in female only in the following groups (10-14), (15-19) and (35-39). And no female or male patients with SLE in the following groups (40-44), and (50-54). Some studies have shown that the prevalence of RF and other auto antibodies in general population tends to decline beyond the age of 70 years to 80 years [6]. This decrease may be related to an increased mortality rate among autoantibody-positive individuals, but in the study sample because of short life expectancy in comparison to the western countries and because of inability of the elderly people to contact health system due to their low socioeconomic State. Further studies include HLA-D locus situated on chromosome 6 in man. Research on etiology of the diseases association with human leucocytes antigen drew attention to the possibility of genetic predisposition coded at or near the HLA-D locus immune response gene which may be in linkage disequilibria with HLA-D locus [14].

This study revealed the effect of increase of ANA, RF and CRP in Patients with Rheumatic Symptoms, SLE and/or RA. This study covered nearly the details for this correlation that does not discussed enough in other studies [4-10].

\section{References}

1. Solomon D, Kavanaugh A, Schur P (2002) American college of rheumatology ad hoc committee on immunologic testing: evidence-based guidelines for the use of immunologic test: antinuclear antibodies testing. Arthritis Rheum 47: 546-555.

2. Hamilton RNR, Detrick B (2002) Manual of clinical immunology (6th edtn) ASM press. Washington D C, USA.

3. Christoper H, Edwin R, Chilvers N, Nicki R, (2002) Davidson's, Principles and Practice of Medicine. (19th edtn).

4. Firestein Gs, Panayi GS, Wollheim FA (2000) Rheumatoid arithritis: New frontiers in pathogenesis and treatment. Oxford: Oxford University Press, England, UK.

5. Bobbio F, Alpini C, Caporali R, Avalle S, Bugatti S, et al. (2004) Autoantibody profile in rheumatoid arthritis during long-term infliximab treatment. Arthritis Res Ther 6: R264-R267. 
Citation: Bamujaly A (2017) ANA, RF and CRP in Patients with Rheumatic Symptoms (SLE and/or RA) in the King Abdul-Aziz Hospital-JeddahSaudi Arabia. J Gen Pract (Los Angel) 5: 290. doi:10.4172/2329-9126.1000290

Page 4 of 4

6. Frances, Fischbach (2004) A manual of laboratory and diagnostic tests. (7 edtn) Lippincott Williams \& Wkins. Philadelphia, USA.

7. Stephen E (2001) Effects of drugs on clinical laboratory tests. Archives of Pathology \& Laboratory Medicine 125: 844-844.

8. Kelly H, Harris A, Ruddy F, Sledge W (1997) Text Book of Rheumatology (5th edtn). USA.

9. Arkadiusz K, Maria M, Dorota S, Ewa W, Magdalena D (2013) Relationship between rheumatoid arthritis activity and antithyroid antibodies, Polskie Archiwum Medycyny Wewnętrznej 123: 394-400.

10. McGhee J, Kickingbird L, Jarvis J (2004) Clinical utility of antinuclear antibody test in children. BMC Pediatr 4: 13.

11. Kavanaugh A, Tomar R, Reveille J, Solomon DH, Homburger HA (2000) Guidelines for clinical use of the antinuclear antibody test and tests for specific autoantibodies to nuclear antigens. American College Pathologists. Arch Pathol Lab Med 124: 71-81.

12. Papiha S, Lanchbury J, Pal B (1986) Genetic structure of the population with rheumatoid arthritis in north east England: A genetic approach to define different subtypes. Annals of the Rheum Dis 45: 881- 891 .

13. Moore TL, John W, Old Father (1984) HLA antigens in black and white patients with juvenile arthritis; association with rheumatoid Factor, hidden rheumatoid factor, antinuclear antibody and immune complex levels. The J of Rheum 11: 188-196.

14. Nakano M, Ohuchi Y, Hasegawa H (2000) Clinical significance of anticentromere antibodies in patients with systemic lupus erythematosus. J Rheum 27: 1403-1410. 